\title{
Two Phase Flow Experimental Study Inside a Microchannel: Influence of Gravity Level on Local Boiling Heat Transfer
}

\author{
Sébastien Luciani \\ Institut Universitaire des Systèmes Thermiques Industriels, \\ Université d'Aix Marseille I, \\ Laboratoire IUSTI, \\ Technopôle de Château-Gombert,
}

France

\section{Introduction}

Flow boiling in microchannels is the most complex convective phase change process. Indeed, a lot of physical parameters influence the two-phase flow during boiling. Here, we will focus on the influence of one of this factor: the gravity level. Actually, there are not many mechanisms that have been proposed for the role of this bound on boiling phenomena. In fact, there is not complete agreement on the importance of gravity on heat and mass transfers with phase change because there is a lack of experimental data at this small scale and because reproducing different gravity levels during parabolic flights has a cost. In this line, the goal of this work is to obtain benchmark data on local heat transfer coefficient in a microchannel during normal and microgravity. We want to acquire a better knowledge of the elementary phenomena which control the heat and mass transfers during convective boiling. Indeed, boiling in microscale geometry is a very efficient mode of heat transfer since high heat and mass transfer coefficients are achieved. Actually, microchannels are widely used in industry and they are already attractive in many domains such as design of compact evaporators and heat exchangers. They provide an effective method of fluid movement and they have large heat dissipation capabilities. In these situations, their compact size and heat transfer abilities are unrivalled. In this chapter, the objective is to acquire better knowledge of the conditions that influence the two-phase flow under normal and microgravity. The expected results will contribute to the development of microgravity models. To perform these investigations, we used an experimental data coupling with an inverse method based on BEM (Boundary Element Method). This non intrusive approach allows us to solve a 3D multi domain IHCP (Inverse Heat Conduction Problem). With this analysis, we are able to quantify the local heat flux, the local temperature and the local heat transfer coefficient in a microchannel $(254 \mu \mathrm{m})$ by inversing thermocouples data without disturbing the established flow. 


\begin{tabular}{|c|c|c|}
\hline Symbol & Description & Unit \\
\hline $1 \mathrm{~g}$ & Terrestrial gravity $\left(9,81{\left.\mathrm{~m} . \mathrm{s}^{-2}\right)}^{2}\right.$ & $\mathrm{m} . \mathrm{s}^{-2}$ \\
\hline $1,8 \mathrm{~g}$ & Hypergravity $\left(17,66 \mathrm{~m} \cdot \mathrm{s}^{-2}\right)$ & $\mathrm{m} . \mathrm{s}^{-2}$ \\
\hline$\mu \mathrm{g}$ & Microgravity (+/- 0,05 m.s-2) & $\mathrm{m} \cdot \mathrm{s}^{-2}$ \\
\hline $\operatorname{Re}$ & Reynolds number & \\
\hline Bo & Bond number & \\
\hline $\mathrm{D}_{\mathrm{h}}$ & Hydraulic diameter & $\mathrm{mm}$ \\
\hline $\mathrm{T}$ & Temperature & ${ }^{\circ} \mathrm{C}$ \\
\hline$h$ & Heat transfer coefficient & $\mathrm{W} \cdot \mathrm{m}^{-2} \cdot \mathrm{K}^{-1}$ \\
\hline $\mathrm{Q}_{\mathrm{w}}$ & Heat flux density & $\mathrm{kW} \cdot \mathrm{m}^{-2}$ \\
\hline $\mathrm{L}_{\mathrm{c}}$ & Capillarity length & $\mathrm{m}$ \\
\hline$x$ & Constant distance & $\mathrm{m}$ \\
\hline$S$ & Section & $\mathrm{m}^{2}$ \\
\hline $\mathrm{L}_{\mathrm{v}}$ & Heat of vaporization & kJ.kg-1 \\
\hline $\mathrm{F}_{\mathrm{k}}$ & Dimensionless number & \\
\hline$A$ & Matrix & No unit \\
\hline$B$ & Right hand vector & No unit \\
\hline$X$ & Vector of the unknowns & No unit \\
\hline$U, V$ & Orthogonal matrices & No unit \\
\hline$W$ & Diagonal matrix & No unit \\
\hline \multicolumn{3}{|c|}{ Greek symbol } \\
\hline$\phi$ & Heat flux density & W.m-2 \\
\hline$\lambda$ & Conductivity & W.m $\mathrm{m}^{-1} \cdot \mathrm{K}^{-1}$ \\
\hline$\chi_{\mathrm{v}}$ & Vapour quality & \\
\hline$\theta$ & Temperature & ${ }^{\circ} \mathrm{C}$ \\
\hline$\sigma$ & Surface tension & N.m ${ }^{-1}$ \\
\hline$\rho$ & Density of the fluid & Kg.m ${ }^{-3}$ \\
\hline \multicolumn{3}{|c|}{ Subscripts } \\
\hline$l$ & Liquid & \\
\hline$v$ & Vapour & \\
\hline sat & Saturated & \\
\hline $\bmod$ & Modeled & \\
\hline meas & Measured & \\
\hline \multicolumn{3}{|c|}{ Superscripts } \\
\hline \multicolumn{3}{|c|}{ Abbreviations } \\
\hline BEM & Boundary Element Method & \\
\hline IHCP & Inverse Heat Conduction Problem & \\
\hline ESA & Europe Space Agency & \\
\hline CNES & Centre National d'Etude Spatiale & \\
\hline
\end{tabular}

Table 1. Nomenclature 


\section{State of the art}

One of flow boiling characteristics is the high value of heat transfer coefficient which offers possibility of transferring huge heat fluxes. It means that nowadays, minichannels and microchannels cooling elements and heat exchangers are widely applied in industry where they enable huge heat flux density. Here, boiling flows in microchannels are particularly interesting since the heat transfers can be applied to heat exchange processes and energy conversion. In that way, they can be used as microcooling elements. Indeed, all the outgoings concerning industrial investigations are based on the fact that convective boiling provides effective heat transfer mode. That's why the physical mechanisms which occur during the phase change need to be well studied in order to have better understanding of the major parameters that influences the heat transfers.

In fact, the heat transfer process and hydrodynamics occurring in these channels are distinctly different than that in macroscale flows (Carey, 1992), so only some of the available macroscale knowledge can be applied to the microscale. Recently, a number of papers have appeared on experimental investigations and theoretical analysis of flow boiling inside minichannels for various geometry scales. Exhaustive reviews by (Kandlikar, 2001) and (Tadrist, 2007) are providing a state of the art of many aspects of boiling heat transfer and actually studies are still under investigations. In 1998, (Yan \& Kenning, 2000) observed high surface temperature fluctuations in a minichannel of 1,33 mm-hydraulic diameter. Surface temperature fluctuations $\left(1\right.$ to $2{ }^{\circ} \mathrm{C}$ ) are caused by grey level fluctuations of liquid crystals. The authors evidenced a coupling between flow and heat transfer by obtaining the same fluctuation frequencies between the surface temperature and two-phase flow pressure fluctuations. (Kennedy et al., 2000) studied convective boiling in circular minitubes of $1,17 \mathrm{~mm}$-diameter and focused on the nucleate boiling and unsteady flow thresholds using distilled water. They obtained these results experimentally analyzing the pressure drop curves of the inlet mass flow rate for several heat fluxes. (Qu \& Mudawar, 2003) found two kinds of unsteady flow boiling. In their parallel microchannel arrays, they observed either a spatial global fluctuation of the entire two-phase zone for all the microchannels or anarchistic fluctuations of the two-phase zone: over-pressure in one microchannel and under-pressure in another. Besides, flow visualization analysis has previously been realized. (Brutin \& Tadrist, 2003) realize flow visualization analysis. They developed a model based on a vapour slug expansion and defined a nondimensioned number to characterize the flow stability transition. Based on this criterion they proposed pressure loss, heat transfer, and oscillation frequency scaling laws. These characteristics number allows us to analyze quite well the experimental results. It highlights the coupling phenomena between the liquid-vapour phase change and the inertia effects. Previous studies discuss about evaporation in microchannels (Hestroni et al, 2005; Tran \& Wambsganss, 1996). It is thought that the best heat transfer mechanism is the evaporation of the thin liquid film around the bubbles. There are several general literature reviews on the subject (Thome, 1997). However, mechanisms concerning the development and the progression of a liquid-vapour interface through a minichannel are still unclear. Physical phenomena such as bubble confinement (Kew \& Comwell, 1997) and thin film evaporation have been recorded by researchers, and subsequently attempts have been made to explain these observations. It is thought that surface tension, capillary forces and wall effects are dominant in small diameter channels. Various phenomena are observed as the bubble diameter approaches the channel diameter; the bubbles become more confined. This is the 
typical situation at vapour qualities above 0.05 , the channels diameter become so confining that only one bubble exists in the cross section, sometimes becoming elongated. This is in stark contrast to flows seen in macrochannels, where numerous bubbles can exist at one time. As a result, many types of instabilities can develop in flow boiling. Concerning convective boiling in minichannels such as we used, few papers deal with instabilities: flow excursion is the most common one explained in a classical minichannel diameter by the Ledinegg criterion (Ledinegg, 1938). Unsteady flows and flow boiling instabilities are mainly related to the confined effects on bubble behaviour in the microducts, (Kew \&.Comwell, 1994) highlighted an appearance threshold of the instabilities phenomena when the starting diameter of the bubble approaches the hydraulic diameter of the minichannel.

However, concerning the microgravity investigations, there are not many studies in the case of the two-phase flows with phase shift. The effects of gravity mainly seem to result in the modifications of structure (topology) of the flows. Nevertheless, new experimental data are necessary to clarify these points because there is less references in literature which study the effect of gravity on flow boiling. In this paper, we will present some results illustrated the influence of gravity of the flow.

The scientific results obtained concern bubble formation during convective boiling in a minichannel under microgravity and the associated heat transfer coefficient. Here, we are dealing with saturated flow boiling. In our experiment and according to (Carey, 1992), we observed several flow behaviours (Fig. 1). At low quality, the flow is found to be in the bubbly flow regime, which is characterized by discrete bubbles of vapour disturbed in a continuous liquid phase (the mean size of the bubbles is small compared to the diameter of our tube). At slightly higher qualities, we observed smaller bubbles which coalesce into slugs.
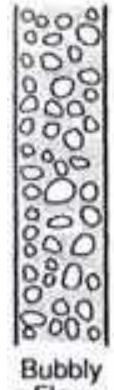
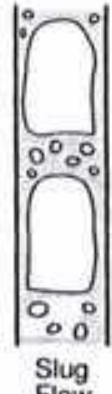
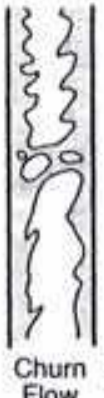
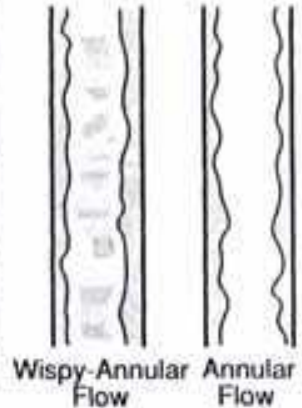

Fig. 1. Schematic representations of flow regimes observed in vertical gas-liquid flow.

As a result, when boiling is first initiated, bubbly flow exists. Increasing quality typically produces transitions from bubbly to plug flow, plug to annular flow and annular flow to mist flow. We observed all this flow properties in our channels but the effects are different when we passed from terrestrial gravity to microgravity. Indeed, during the transitions levels, there are some instabilities occurring which disturb the flow regimes. In reality, during the experimental activities, we observed many types of unsteady related to the gravity which changes during the parabolic flights.

Nethertheless, whatever the gravity level is, when boiling is initiated, both nucleate boiling and liquid convection are active. As vaporization occurs, the void fraction rapidly increases at low to moderate pressures. As a result, the flow accelerates, which tends to enhance the convective transport from the heated wall of the channel. In our case, we used a uniform 
heat flux so that we can observe that the wall-to-interface temperature difference needed to drive the heat flux is reduced.

\section{Experimental investigation}

On convective boiling recent works tend to establish correlations between the physical parameters of the experiment and the heat transfer coefficients but only related to the transfers in normal gravity. Plus, they only are dedicated to global heat transfer phenomenon. Then, in order to constitute a starting point for the space applications, it is necessary to quantify the differences produced by the gravity levels and to set up local analysis on the transfers. The objectives of experimental work discussed are as follows:

- The experimental procedure

- The estimation of the local heat transfer coefficient

- The analysis of the selected factors that influence convective boiling (gravity level, heat flux, vapour quality)

\subsection{Conception}

\subsubsection{Loop system}

The objective is to determine the local heat transfer coefficient in a minichannel and to study the influence of gravity on flow structures under several gravity levels. Two phase flow has been induced in a minichannel placed vertically. Images and video sequences have been achieved with a high speed camera. The experiments are conducted with a transparent, nonflammable and non-explosive fluid, which has a low boiling temperature $\left(61 \pm \pm^{\circ} \mathrm{C}\right.$ at 1013.15 $\mathrm{hPa}$ compared with $100 \pm^{\circ} \mathrm{C}$ for water) and three hydraulic diameters (Dh) are investigated: $0.49 \mathrm{~mm}\left(6 \times 0,254 \mathrm{~mm}^{2}\right) ; 0.84 \mathrm{~mm}\left(6 \times 0.454 \mathrm{~mm}^{2}\right)$ and $1.18 \mathrm{~mm}\left(6 \times 0.654 \mathrm{~mm}^{2}\right)$.

\subsubsection{Dimension of the channel}

We present here one minichannel. The dimensions are as follows: $50 \mathrm{~mm}$ long, $6 \mathrm{~mm}$ broad and $254 \mu \mathrm{m}$ deep (Fig. 2). The minichannel is modelled as a rectangular bar: a cement rod $\left(\lambda=0.83 \mathrm{~W} \cdot \mathrm{m}^{-1} \cdot \mathrm{K}^{-1}\right)$ and a layer of inconel ${ }^{\circledR}\left(\lambda=10.8 \mathrm{~W} \cdot \mathrm{m}^{-1} \cdot \mathrm{K}^{-1}\right)$ in which the minichannel is engraved. Above the channel, there is a series of temperature and pressure sensors and inside the cement rod, 21 thermocouples (of Chromel-Alumel type) are located at a height of nearly $9 \mathrm{~mm}$ and are also distributed lengthwise (Fig. 3). They enable us to acquire the temperature in various locations $(x, y$ and $z)$ of the device.

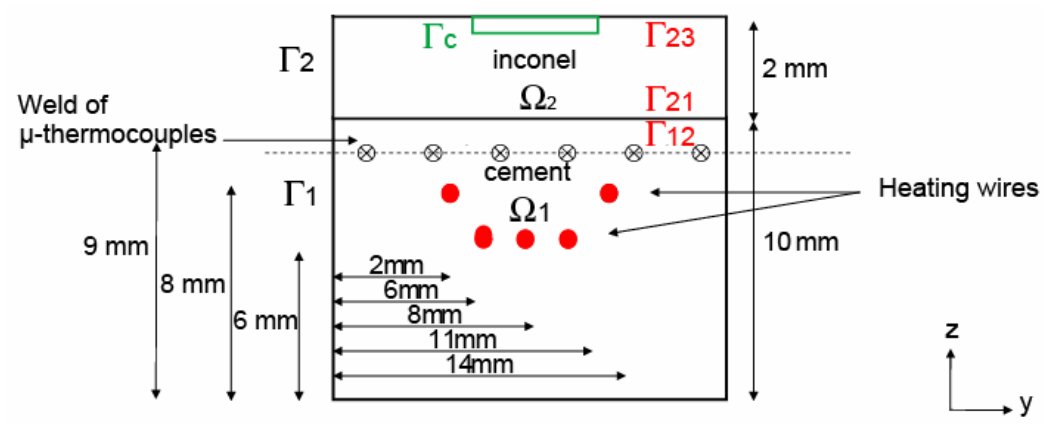

Fig. 2. Front view of the device, we can see the 2 domains. 
These K-type thermocouples (diameter of $140 \mu \mathrm{m}$ ) are used to measure the temperatures of the cement rod at several locations in the minichannel under the heating surface.

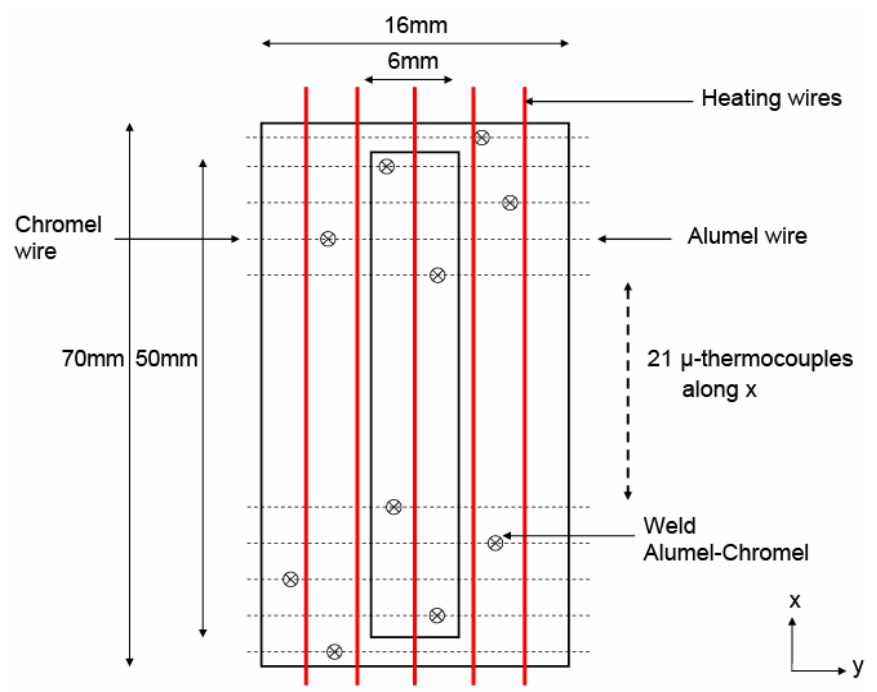

Fig. 3. Top view of the device.

Here is present a X-ray tomography of the thermocouples and heating wires (Fig. 4):

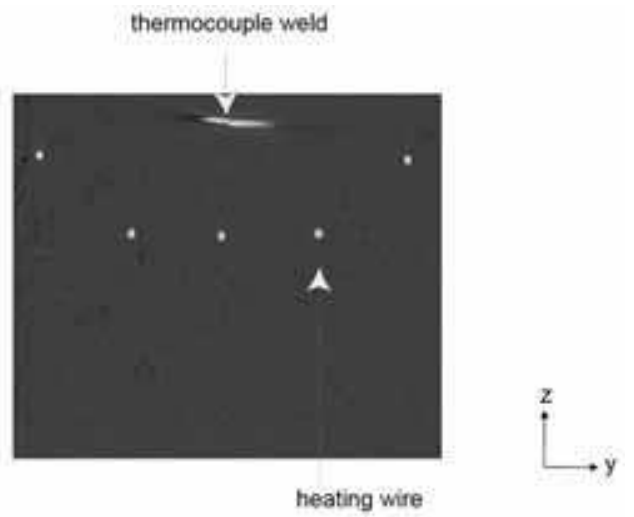

Fig. 4. X-ray tomography of the cement rod.

We can see inside the cement rods 5 heating wires. The heating wires are used to provide the power $\left(33 \mathrm{~W} \cdot \mathrm{m}^{-1}\right)$ necessary to obtain a biphasic flow.

To observe the influence of gravity on the flow and the behaviour of the convective boiling, 2 instrumented test-tubes are embarked during the parabolic flights; one for the visualization using a fast camera and the other one for the acquisition of data using thermocouples (Fig. 5). They make it possible to check the influence of gravity on the temperatures and pressures measurements for 3 levels of gravity: terrestrial gravity (1g), hypergravity $(1,8 \mathrm{~g})$ and microgravity $(\mu \mathrm{g})$. 


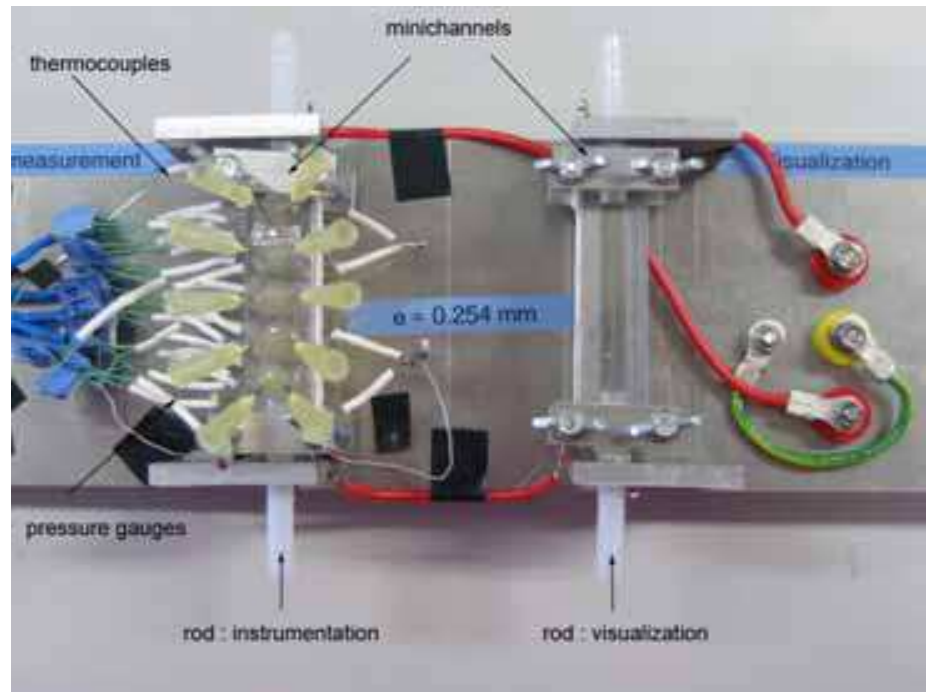

Fig. 5. Coupling of the two minichannels used during parabolic flights (left minichannel for measurements - right minichannel for visualization).

\subsection{Experience in microgravity}

\subsubsection{On board experiment}

The experimental activities are performed in the frame of the MAP (Microgravity Application Program) Boiling project founded by ESA and embarked on A300-ZeroG to perform three Parabolic Flights campaigns. The experimental device has been embarked on board A300 Zero-G to perform three Parabolic Flights campaigns. The Airbus A-300 Zero G parabolic flight generally executes a series of 31 parabolic manoeuvres during a flight. The aircraft executes a series of manoeuvre called parabola each providing 20 seconds of reduced gravity, during which we are able to perform experiments and obtain data that we are presenting here. During a flight campaign, there are 3 flights with around 31 parabola begin executed per flight. The period between the start of each parabola is 3 min (Fig. 6):

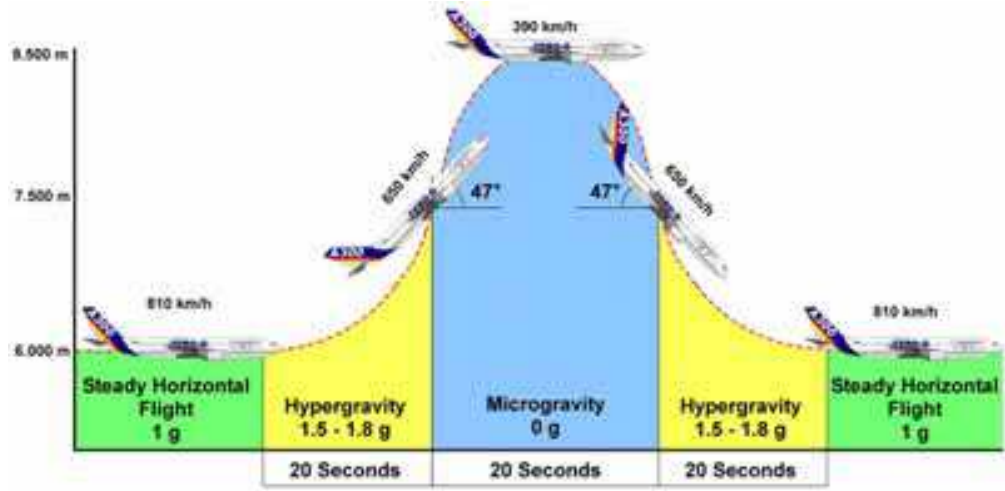

Fig. 6. The different gravity levels occurring during a parabola. 
Each manoeuvre begins with the aircraft flying in a steady horizontal position, with an approximate altitude and speed of respectively $6000 \mathrm{~m}$ and $810 \mathrm{~km} . \mathrm{h}^{-1}$. During this steady flight, the gravity level is $1 \mathrm{~g}$. At a set point, the pilot gradually pulls the nose of the aircraft and it starts climbing. This phase lasts about 20 seconds during which the aircraft experiences an acceleration between 1,5 and 1,8 g times the gravity level. At an altitude of 7500 meters, with an angle around 47 degrees to the horizontal and with air speed of 650 $\mathrm{km} \cdot \mathrm{h}^{-1}$, the engine thrust is reduced to the minimum required to compensate.

At this point, the aircraft follows a free-fall ballistic trajectory, i.e. a parabola, lasting approximately 20 seconds during which the gravity is near zero - the microgravity phase begins. The peak of the parabola is achieved at around 8500 meters where the speed is about $390 \mathrm{~km} . \mathrm{h}^{-1}$. At the end of this period when the altitude is $7500 \mathrm{~m}$, the aircraft must pull out the parabolic arc, a manoeuvre which gives rise to another 20 seconds period of $1,8 \mathrm{~g}$, we are in hypergravity. At the end of the 20 seconds, the aircraft flies a steady horizontal path at $1 \mathrm{~g}$ maintaining an altitude of $6000 \mathrm{~m}$.

\subsubsection{Microgravity observation}

We show the results in microgravity. Concerning the flow behaviour, generally, microgravity conditions lead to a larger bubble size which is accompanied by deterioration in the heat transfer rate. For low quality, gravity influence is not negligible. On Fig. 7, we see, for a vertical minichannel, the different flow behaviours during evaporation (Carey, 1992):

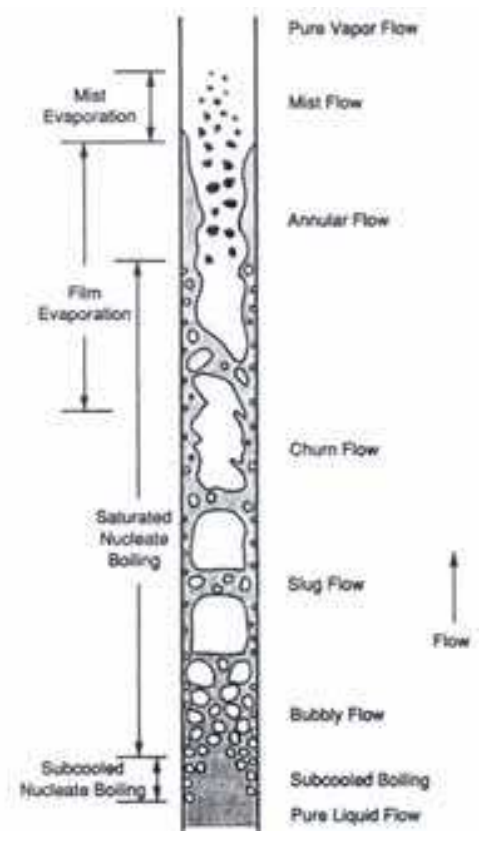

Fig. 7. Vertical co-current flow behaviour with evaporation.

The Fig. 8 shows a typical 3D flow scheme in our minichannel which occurs during a parabola depending on the heat flux density. 


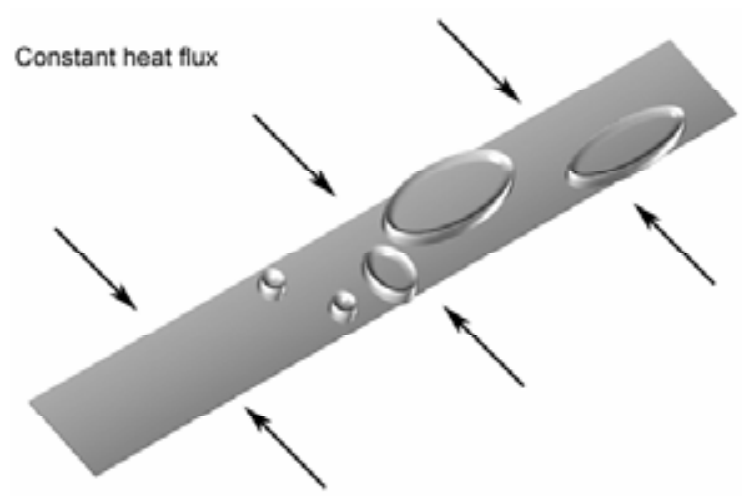

Fig. 8. Typical 3D flow scheme occurring in our minichannel.

The differences introduced by gravity level on flow structures are obtained using the data of parabolic flights (PF63) in March 2007. The analysis (Fig. 9) of the movies recorded highlights that on the minichannel inlet the flow has a low percentage of insulated bubbles. The more significant the sizes of the bubbles are, the larger the surface of the super-heated liquid is. Besides, concerning the microgravity phase, the results present variations compared to the terrestrial gravity and the hypergravity, which shows an influence of the gravity level on the confined flow boiling.

To avoid the high wall temperatures and the poor heat transfer associated with the saturated film boiling regime, the vaporization must be accomplished at low superheat or low heat flux levels.

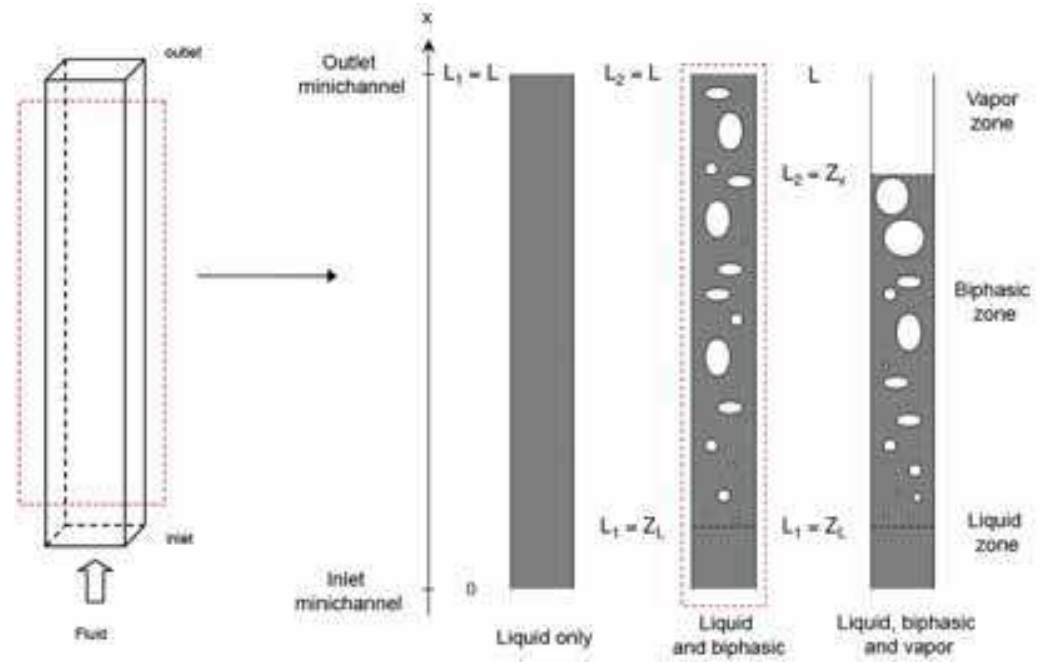

Fig. 9. Flow boiling analysis in our minichannel using a fast cam.

The thermal study of the transfers confirms a higher heat transfer coefficient in the input minichannel during the phase of microgravity (Fig. 13). This decrease is due to the decrease in size of the vapour bubbles. 
On Fig. 10 and Fig. 11, we plot the evolution of the flow in respectively terrestrial and microgravity phase during nearly 20 seconds. We can see that there are very big differences with the structure of the bubbles. In terrestrial gravity, we have bubbly flow profiles while in microgravity we deal with slug and churn flow according to Fig. 7. Here, we can see the observations made in terrestrial gravity:

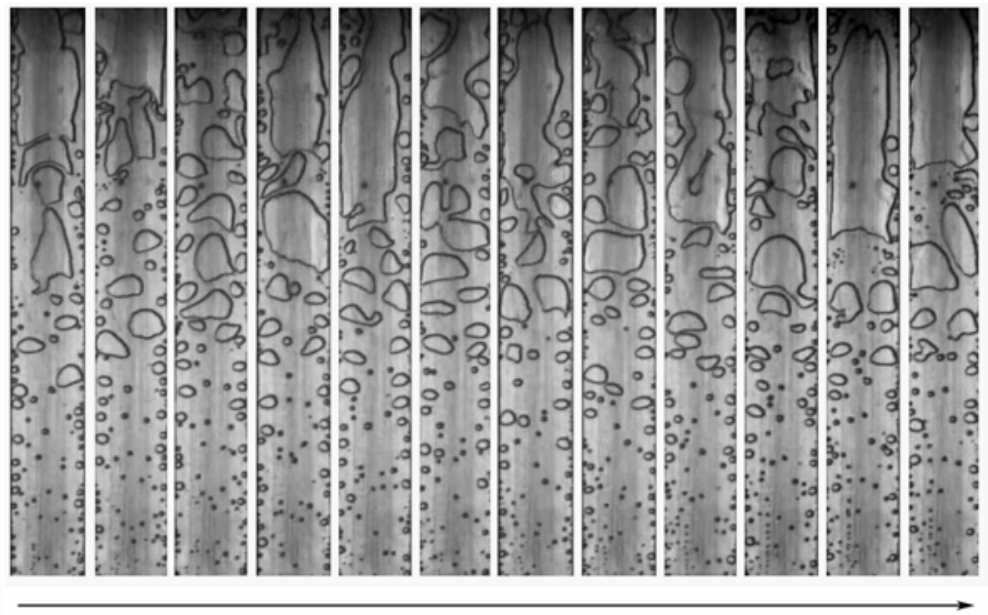

Time

Fig. 10. Flow boiling occurring in our minichannel under terrestrial gravity phase (20 seconds, $\mathrm{Q}_{\mathrm{w}}=45 \mathrm{~kW} \cdot \mathrm{m}^{-2}$ ).

Then in microgravity, we observed the flow sequence which evidences a different topology and particularly with the bubble's size.

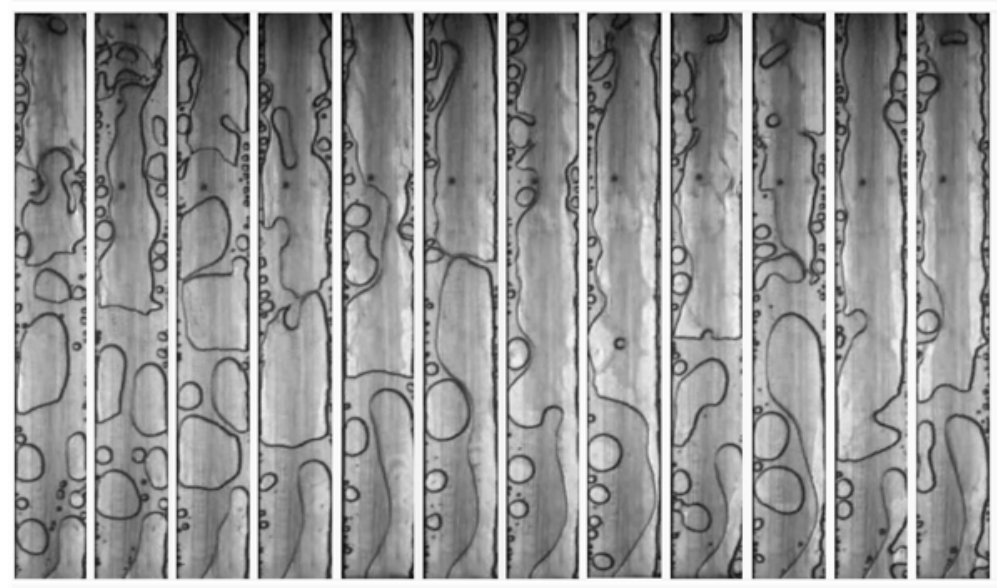

Time

Fig. 11. Flow boiling occurring in our minichannel under microgravity phase (20 seconds, $\mathrm{Q}_{\mathrm{W}}=45 \mathrm{~kW} \cdot \mathrm{m}^{-2}$ ). 


\subsection{Bubble behaviour}

To understand fully the role of microgravity on flow boiling and particularly on the bubbles patterns, we introduce the capillarity length. In fluid mechanics, capillary length is a characteristic length scale for fluid subject to a body force from gravity and a surface force due to surface tension. This number function of the

$$
\mathrm{L}_{\mathrm{c}}=\sqrt{\frac{\sigma}{\rho \mathrm{g}}}
$$

We can see that the capillarity length depends on $\mathrm{g}^{-0.5}$. Or $\mathrm{g}$ is the only parameter that changes during a parabola at a constant mass flow and heat flux rate. Thus when we pass from $1 \mathrm{~g}$ to $1.8 \mathrm{~g}, \mathrm{~L}_{\mathrm{c}}$ decreases of $74 \%$ whereas when we pass from $1 \mathrm{~g}$ to $\mu \mathrm{g}$, $\mathrm{L}_{\mathrm{c}}$ increases of nearly $1400 \%$. This may explain the different sizes of the bubbles during microgravity. Whatever the gravity level, as soon as the vapour occupies the entire minichannel, the heat transfer coefficient decreases strongly to reach a level which characterizes a kind of vapour phase heat transfer. Furthermore, as soon as the vapour completely fills the pipe, the heat exchange strongly falls (Fig. 18). The thermal study of the transfers confirms a higher heat transfer coefficient in the input minichannel during the phase of microgravity.

\subsection{Validation}

\subsubsection{Kandlikar's correlation}

Very recently, (Kandlikar, 2001) proposed a correlation (see below) as a fit to a very broad spectrum of data for flow boiling heat transfer in vertical and horizontal channels:

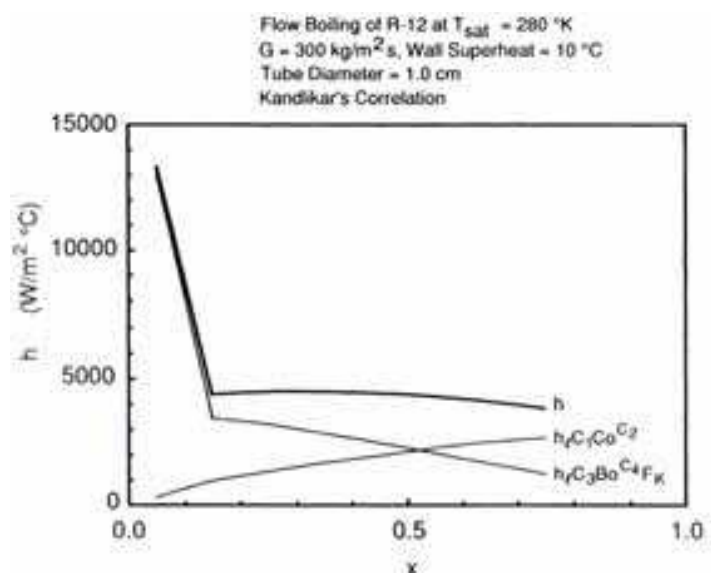

Fig. 12. Convective boiling heat transfer coefficient variation with quality level $x\left(\right.$ here $\left.\chi_{\mathrm{v}}\right)$ for Kandlikar's correlation.

$$
\begin{gathered}
h=h_{1}\left[C_{1} C_{o} C_{2}\left(25 F_{l e}\right)^{C_{5}}+C_{3} B{ }^{C_{4}} F_{K}\right] \\
C_{o}=\left(\frac{1-x}{x}\right)^{0.8}\left(\frac{\rho_{v}}{\rho l}\right)^{0.5}
\end{gathered}
$$




$$
\mathrm{Fr}_{\mathrm{le}}=\frac{\mathrm{G}^{2}}{\rho_{\mathrm{l}}^{2} \mathrm{gD}_{\mathrm{h}}}
$$

The table below are useful to calculate the Fk number.

\begin{tabular}{|c|c|}
\hline Fluid & Fk \\
\hline Water & 1.00 \\
\hline R-11 & 1.30 \\
\hline R-12 & 1.50 \\
\hline R-13B1 & 1.31 \\
\hline R-22 & 2.20 \\
\hline Nitrogen & 4.70 \\
\hline Neon & 3.50 \\
\hline Fluid & Fk \\
\hline Water & 1.00 \\
\hline R-11 & 1.30 \\
\hline
\end{tabular}

Table 2. List of Fk values for different fluids

\subsubsection{Experimental results}

The results are in good agreement with the correlation (Fig. 13). Concerning the range from 0 to $5000 \mathrm{~W} \cdot \mathrm{m}^{-2} \cdot \mathrm{K}^{-1}$, we can see that the experimental curves in terrestrial gravity have the same curvature with the theoretical correlation. Indeed, we have the same level.

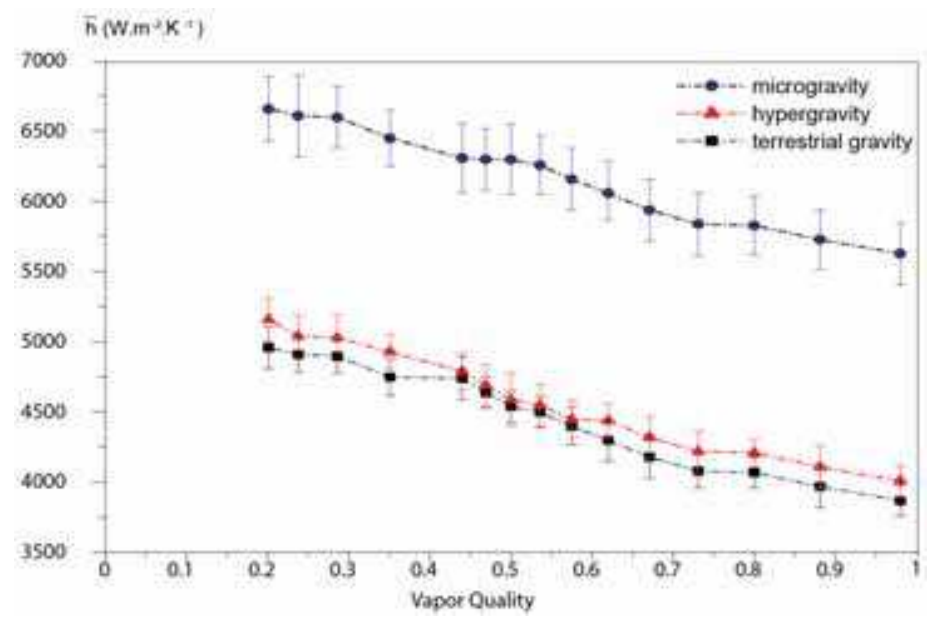

Fig. 13. Influence of vapour quality on the heat transfer coefficient in the minichannel $\left(\mathrm{Q}_{\mathrm{w}}=45 \mathrm{~kW} \cdot \mathrm{m}^{-2}\right)$.

\subsubsection{Featuring experiments}

We can see that we have been able to quantify the heat transfers inside our minichannels and to validate the experimental results in normal gravity with correlation found in literature. So for terrestrial conditions, the results are validated. 
Now, we are going to present more results concerning the influence of three parameters on the heat transfers: the gravity level, the Reynolds number and the Vapour quality. We are presenting and analysing experimental results.

\section{Heat transfer results}

\subsection{Inverse method}

Here, we introduce quickly the estimation method to explain how we estimate our parameter (Le Niliot, 2001). It consists in inversing experimental data measurements (thermocouples) to obtain the surface temperature and the surface flux density in the minichannel. The inverse problem deals with the resolution of IHCP (Beck et al, 1985) where we want to estimate the unknown boundary conditions on the surface minichannel. The numerical method used here is the BEM (Brebbia et al, 1984). This method has been applied in our laboratory for several years to solve inverse problems (Le Niliot et Lefèvre, 2001). $\mathrm{BEM}$ is attractive for our inverse problem resolution because it provides a direct connection between the unknown boundary heat flux, the measurements (thermocouples here) and the linear heat sources (heating wires here). The solution can be obtained by solving a linear system of simultaneous equations without any iterative process.

The estimation procedure consists in inversing the temperature measurements under the minichannel in order to estimate the local boiling heat transfer coefficient $h(x)$, knowing the local heat flux and the local surface temperatures $\left(\varphi_{\text {surface }}, \mathrm{T}_{\text {surface }}\right)$. Those functions of space are the results of the inverse problem. The estimation of the solution is obtained as the solution of the following optimization problem:

\subsubsection{Boundary estimation}

As $N^{\prime}$ is the number of domain $\Omega$ interior points given here by the thermocouples and $N$ the number of boundary elements on our rod, the system has got $\left(\mathrm{N}+\mathrm{N}^{\prime}\right)$ equations. The number of unknowns, noted $\mathrm{M}$, is a function of the boundary conditions applied on the different elements of $\Gamma$ (Fig. 14). Namely for element $\Gamma_{\mathrm{i}}$ we have at least one unknown per element for the following boundary conditions:

First kind condition for which heat flux $\varphi \mathrm{i}$ is unknown and temperature $\theta_{\mathrm{i}}$ is imposed. Second kind condition for which temperature $\theta i$ unknown and heat flux $\varphi_{i}$ is imposed. Third kind condition $\varphi \mathrm{i}=\mathrm{f}(\theta \mathrm{i})$

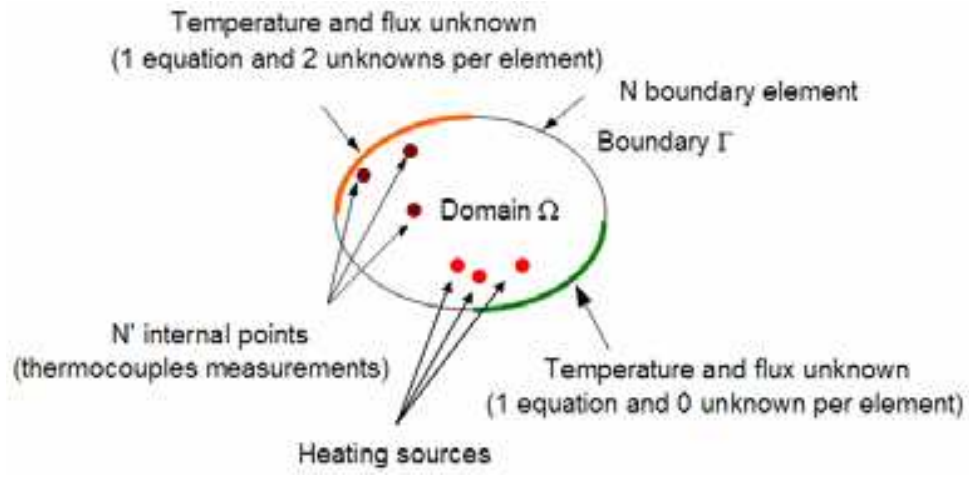

Fig. 14. The problem of the unknown boundary conditions. 
The elements, for which we have one equation, where the boundary condition is missing, let appear two unknowns. The only way to solve the fundamental heat transfer equation is to find some extra information, provided by measurements. In our case, we have interior measurements, given by thermocouples. They enable us with the knowledge of the boundary conditions to solve the problem and to calculate local heat flux and local surface temperatures along the minichannel. This estimation procedure consists in inversing the temperature measurements under the minichannel in order to estimate the local boiling heat transfer coefficient $\mathrm{h}(\mathrm{x})$. Those functions of space are the results of the inverse problem. The estimation of the solution is obtained using BEM as the solution of the following optimization problem:

$$
\hat{\mathrm{T}}_{\text {surface }} \hat{\phi}_{\text {surface }}=\arg \left\{\min \left(\left\|\mathrm{T}_{\text {mod }}-\mathrm{T}_{\text {meas }}\right\|\right)\right\}
$$

In this last expression, the vectors $T_{\text {meas }}$ and $T_{\text {mod }}$ respectively represent the vector of temperature measurements and the vector of the calculated temperatures. The unknown factors $\left(\varphi_{\text {surface }}, \mathrm{T}_{\text {surface }}\right)$ are obtained by minimizing the difference between measurements and a mathematical modeling. Taking into account the specificity of formulation BEM., this minimization is not obtained explicitly but done through a function utilizing a linear combination of measurements. This formulation leads to a matrix system of simultaneous equation :

$$
\boldsymbol{A} X=B
$$

In this last equation, $\boldsymbol{A}$ is a matrix of dimension $\left((\mathrm{N}+\mathrm{N})^{\prime} \times \mathrm{M}\right), X$ the vector of the $\mathrm{M}$ unknowns including $\left(\varphi_{\text {surface }}, \mathrm{T}_{\text {surface }}\right)$ and $B$ of dimension $\left(\mathrm{N}+\mathrm{N}^{\prime}\right)$ is containing a linear combination of the data measurements. If $\mathrm{M}=\mathrm{N}+\mathrm{N}^{\prime}$ we obtain a square system of linear equation but most of the time we have $\mathrm{M}<\mathrm{N}+\mathrm{N}^{\prime}$ and has more equations than unknown (see Sensitivity Study chapter) : our system presents 270 equations for 255 unknown factors (overdetermined system). A solution can be found by minimising the distance between vector $\boldsymbol{A} X$ and vector $B$. In order to find out an estimation $\hat{x}$ of the unknown exact solution $X$, we have to solve the optimization problem using a cost function (5). Assuming that the difference between $\boldsymbol{A} X$ and $B$ can be considered as distributed according a Gaussian law we can find $\hat{X}$ solution of in the meaning of the least squares. Using this last property leads to the Ordinary Least Squares solution :

$$
\begin{gathered}
\hat{X}=\arg \left\{\min \left(\|A X-B\|^{2}\right)\right\} \\
\left(\boldsymbol{A}^{\boldsymbol{T}} \boldsymbol{A}\right) \hat{X}=\left(\boldsymbol{A}^{\boldsymbol{T}} B\right)
\end{gathered}
$$

Actually, the inverse heat condition problem is ill-posed and very sensitive to the measurements errors. Considering the numerical aspects of the inversion, we obtain an illconditioned square matrix $\left(A^{T} A\right)$. Thus, we observe for the system numerical resolution an instability of the solution $\hat{X}$ with regards to the measurements the errors introduced into the vector $B$. As a consequence, we need to obtain a stable the solution of this system by using regularizations tools - Hansen. We propose in the following paragraph an example of 
regularization procedure which can be applied. In order to smooth the solution, we used in our our study the Lanczos decomposition called the the SVD method.

\subsubsection{Regularization using SVD}

The regularization of an inverse problem consists in adding information to improve the stability of the solution with regards to the measurements noise and/or to select a type of solution among all those possible. The ill-conditioned character of matrix $\mathbf{A}$ results in the presence of low singular values. They are a consequence of linear dependent equations : indication of a strong correlation between the unknown factors.

Actually, the SVD method makes possible to deal with 3D inverse problem where the mesh is structured, i.e. the pavements of the elements do not have all the same surfaces and thus the same sensitivity (Fig. 15). This property increased the ill-poseness of the problem. Indeed, the solution is much more unstable when the space discretization is refined. This singular behavior is due to the fact that the conditioning number of the linear system (see the L-curve paragraph) is a function of the power of the meshing step.

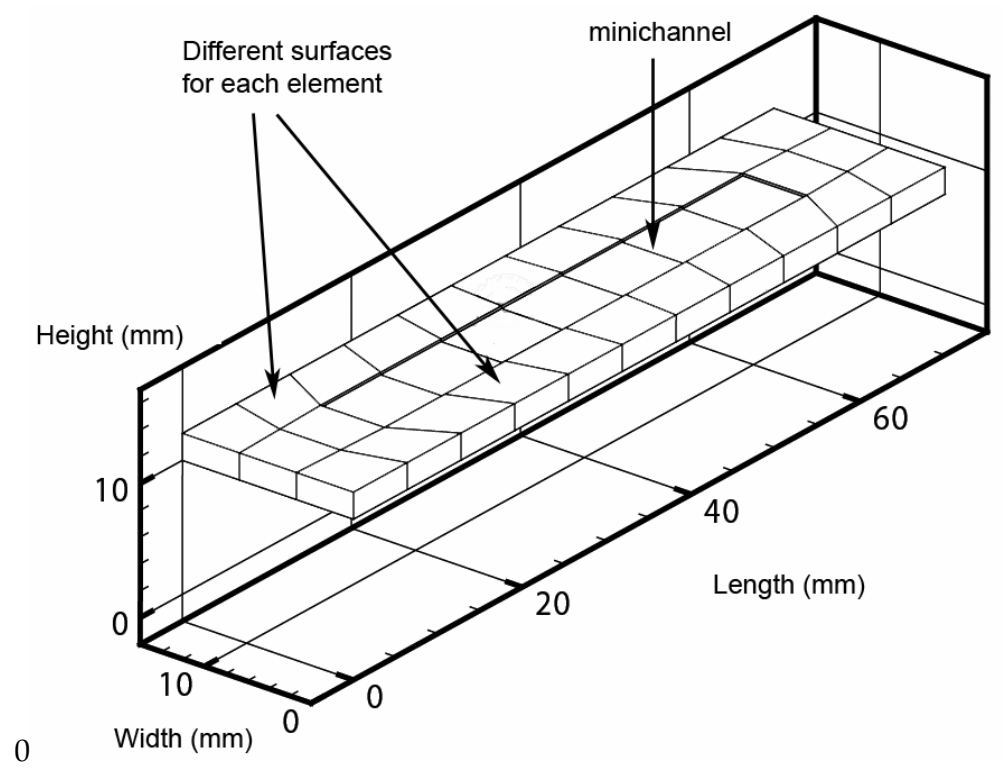

Fig. 15. 3D Meshing- of the minichannel only the faces are meshed.

In our problem, SVD method consists in removing the too small singular values which affect the stability of the system in order to find one solution among several, which best corresponds. It can seem contradictory to improve the system by removing equations and thus information : the suppression of the equations involves a reduction in the rank of our system and consequently an increase in the space of the plausible solutions. However, the action of removing these equations improves the stability because it deliberately removes the equations which disturb the solution. Matrix $\boldsymbol{A}$ can be built into a product of squares matrices ( $U$ and $V$ are orthogonal matrices and $W$ is the diagonal matrix of the singular values $w_{j}$ ) as shown : 


$$
\begin{gathered}
A=U W^{T} \\
X=\left(U^{T} \operatorname{Diag}\left(\frac{1}{w_{j}}\right) V\right) B
\end{gathered}
$$

$\boldsymbol{A}$ is ill-conditioned when some singular values $\mathrm{w}_{\mathrm{j}} \rightarrow 0\left(1 / \mathrm{w}_{\mathrm{j}} \rightarrow \infty\right)$. As a result, the errors are increased. By using SVD, $W^{-1}$ is truncated from the too high $\left(1 / \mathrm{w}_{\mathrm{j}}\right)$.

$$
\mathrm{W}=\left[\begin{array}{lllll}
\mathrm{w}_{1} & \cdots & \cdots & 0 & \\
\vdots & \ddots & & \vdots & \\
\vdots & & \ddots & \vdots & 0 \\
\vdots & & & \ddots & \\
0 & \cdots & \cdots & \cdots & \mathrm{w}_{\mathrm{n}}
\end{array}\right]
$$

The truncated matrix can be built up as in:

$$
\mathrm{W}_{\mathrm{t}}=\left[\begin{array}{lllll}
\mathrm{w}_{1} & \cdots & \cdots & 0 & \\
\vdots & \ddots & & \vdots & \\
\vdots & & \ddots & \vdots & 0 \\
0 & \cdots & \cdots & \mathrm{w}_{\mathrm{p}} & \\
& & 0 & &
\end{array}\right]
$$

The estimate solution vector $\hat{X}$ is function of the new truncated matrix $\mathrm{W}_{\mathrm{t}}^{-1}$ :

$$
\hat{\mathrm{X}}=\left(\mathrm{U}^{\mathrm{T}} \mathrm{W}_{\mathrm{t}}^{-1} \mathrm{~V}\right) \mathrm{B}
$$

We observe like in the regularization method by modifications of the functions to be minimised (for example Tikhonov) a smoothing of the solution. However, it is necessary to explain how is carried out the choice of the singular values ignored. There is a "criteria" making it possible to quantify the balance between a stable solution and low residuals : the condition number. It is defined by the ratio of the highest to the weakest of the singular values of matrix A.

All the singular values lower than a limit value are eliminated. The numerical procedure can be found in the LINPACK or in Numerical recipes (Press et al, 1990). This technique requires the use of a threshold which allows the choice of values to be cancelled. The level of truncation is determined by the technique known as the L-curve (Hansen, 1998).

\subsubsection{The L-curve}

The obtained solution $\hat{x}$ depends on a value selected by the user. To avoid entering extremes and losing information, a tool called L-curve is introduced to estimate the correct condition number. The goal is to trace on a logarithmic scale the norm of the solution on the norm of the residuals $\mathrm{AX}-\mathrm{B} \|$ (Fig. 16).

The optimal value is in the hollow of the $\mathrm{L}$ where the best compromise between stable results and low residuals (on the distinct corner separating the vertical and the horizontal part of the curve). It is around this corner that we find the best compromise. 
Thus, this value makes it possible to define the truncation level and the number of conditioning associated. In our problem, this value is around $10^{7}$, which is very high and shows how ill-posed our system is.

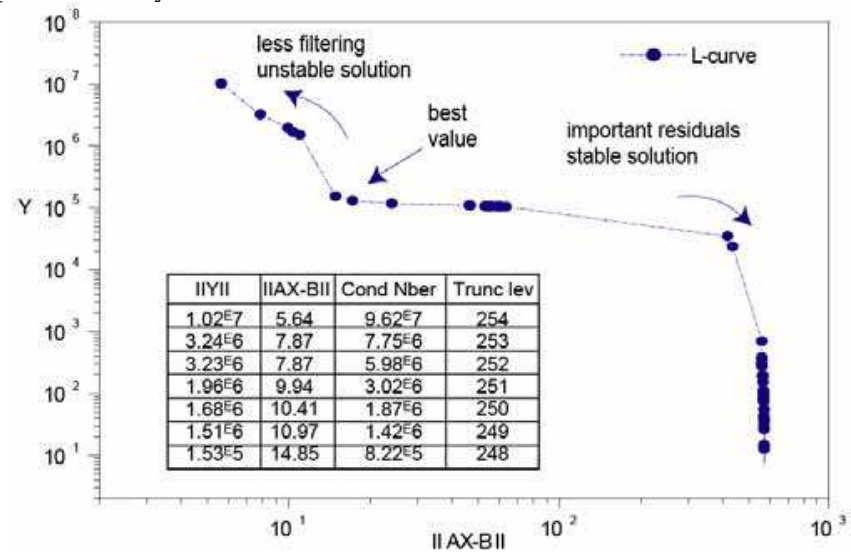

Fig. 16. L-Curve approach applied to the B.E.M

\subsection{Local estimation}

Knowing the estimated surface temperatures $\left(\hat{\mathrm{T}}_{\text {surface }}\right)$ and the surface heat flux $\left(\hat{\varphi}_{\text {surface }}\right)$, we can calculate the local boiling coefficient $\hat{\mathrm{h}}$ in the minichannel knowing the saturation temperature of the liquid $\left(\mathrm{T}_{\text {sat }}\right)$ :

$$
\hat{\mathrm{h}}=\frac{\hat{\phi}_{\text {surface }}(\mathrm{x})}{\hat{\mathrm{T}}_{\text {surface }}(\mathrm{x})-\mathrm{T}_{\text {sat }}}
$$

On Fig. 17, we show the evolution of the local wall temperature and the heat flux function of the minichannel length:

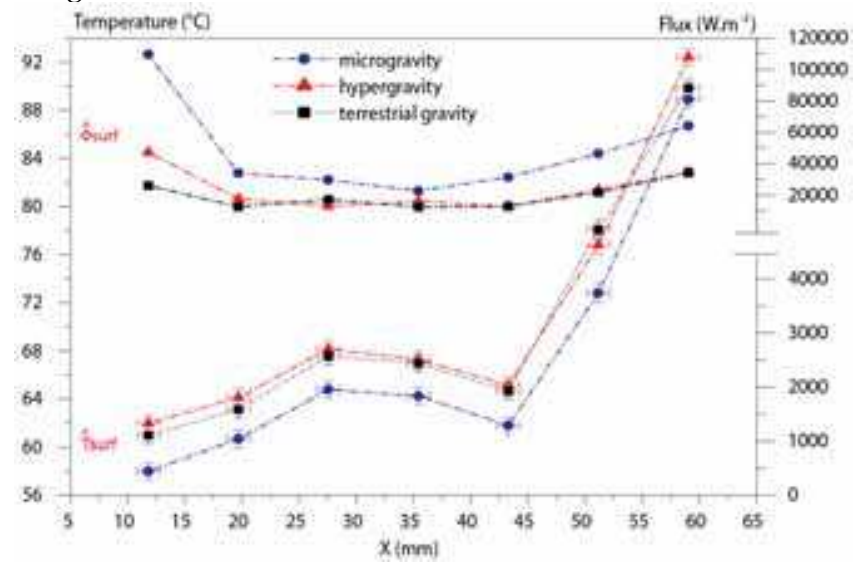

Fig. 17. Influence of gravity on the surface temperature and the heat flux along the minichannel $\left(\mathrm{Q}_{\mathrm{w}}=33 \mathrm{~kW} \cdot \mathrm{m}^{-2}\right)$. 
We observe that the temperature profile increases and that in microgravity, the values are higher. The temperature rises, which is agreement with the temperatures distribution that we used in the inversion procedure. Then we can easily plot the local heat transfer coefficient function of the minichannel length:

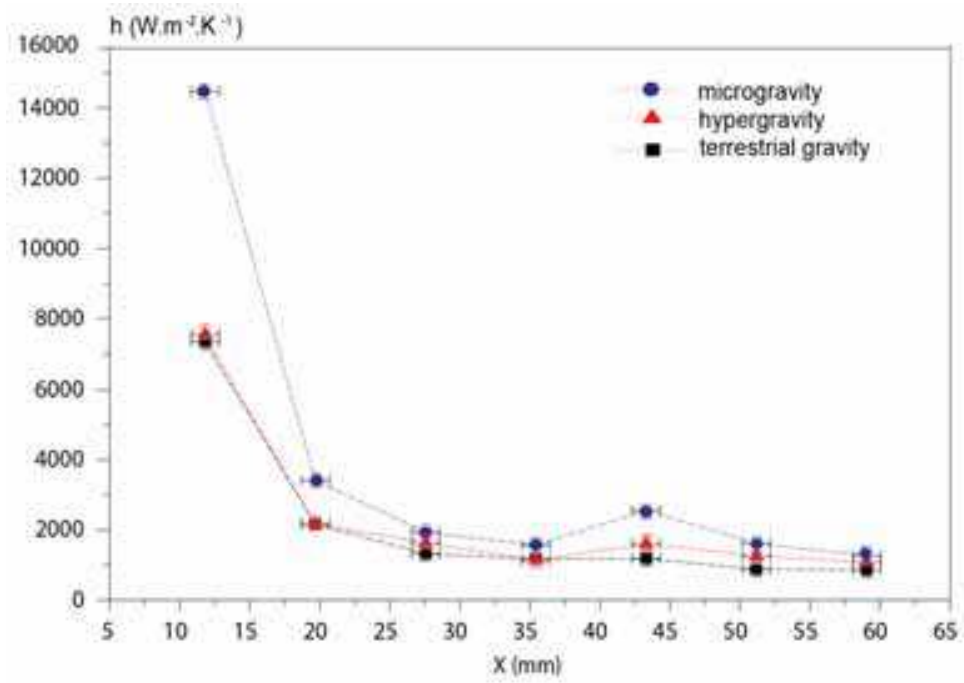

Fig. 18. Influence of gravity on the heat transfer coefficient along the minichannel $\left(Q_{w}=45\right.$ $\left.\mathrm{kW} \cdot \mathrm{m}^{-2}\right)$.

First result shows that during the microgravity period, in inlet of the minichannel $(x=20$ $\mathrm{mm}$ ), the heat transfer coefficient is higher with a value around $15000 \mathrm{~W} \cdot \mathrm{m}^{-2} \cdot \mathrm{K}^{-1}$. This value has to be compared to the $1.8 \mathrm{~g}$ and the $1 \mathrm{~g}$ where it is equal to $7500 \mathrm{~W} \cdot \mathrm{m}^{-2} \cdot \mathrm{K}^{-1}$. Second result indicates that it decreases along the $x$ length in the flow direction. Whatever the gravity level, as soon as the vapour occupies the entire minichannel, the heat transfer coefficient decreases strongly to reach a level which characterizes a kind of vapour phase heat transfer. Furthermore, as soon as the vapour completely fills the pipe, the heat exchange strongly falls because there is no more liquid boiling (Fig. 18) but only heat transfer through the vapour (heat insulator).

\subsection{Reynolds number}

Fig. 19 presents the evolution of the heat transfer coefficient as a function of the Reynolds number. In our configuration, we are in a laminar flow and the curve behaviour is observed for all studied gravity level. Here, we plot the results for a constant heat flux. We can observe two significant results: with the increasing Reynolds number, the heat transfer coefficient increases for each gravity level. Secondly, the average heat transfer coefficient is higher in microgravity. Knowing this, we can propose a global behaviour of the fluid flow in the minichannel. Nucleate boiling is the dominant vaporization mechanism near the onset of boiling. As more vapours are generated in the flow and the void fraction increases, evaporation from the liquid-vapour interface becomes increasingly important. 


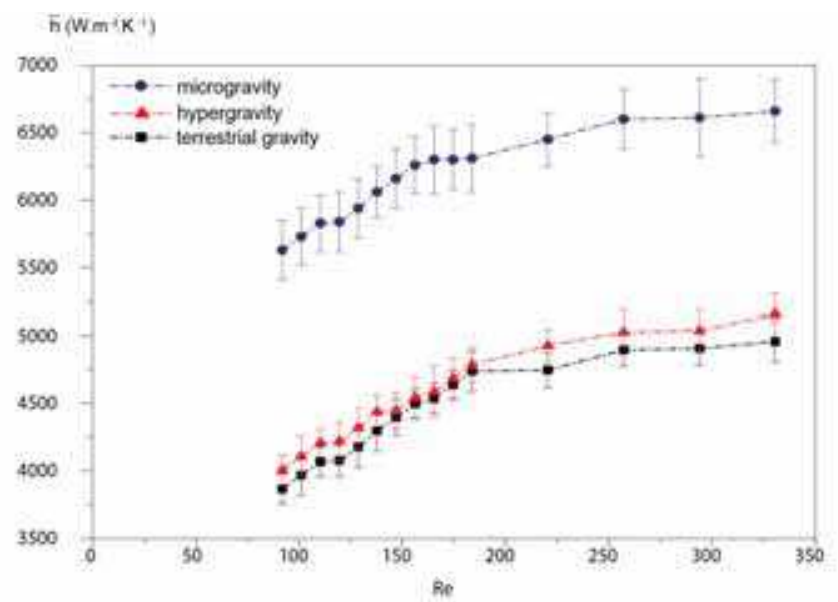

Fig. 19. Influence of Reynolds number on the average heat transfer coefficient in the minichannel $\left(\mathrm{Q}_{\mathrm{w}}=45 \mathrm{~kW} \cdot \mathrm{m}^{-2}\right)$.

\subsection{Local quality}

We plot the local vapour quality as a function of the $x$-axis of the minichannel using the following equation:

$$
\chi_{\mathrm{v}}(\mathrm{x})=\frac{\mathrm{Q}_{\mathrm{w}} \mathrm{x}}{\mathrm{SL}_{\mathrm{v}} \rho_{\mathrm{l}} \mathrm{u}_{\mathrm{v}}}
$$

First results (Fig. 20) show that the local quality increases along the main axis from the inlet to the outlet of the channel. This is in good agreement with the temperature profile we have on the boundary minichannel since at the outlet the temperature is higher (Fig. 17).

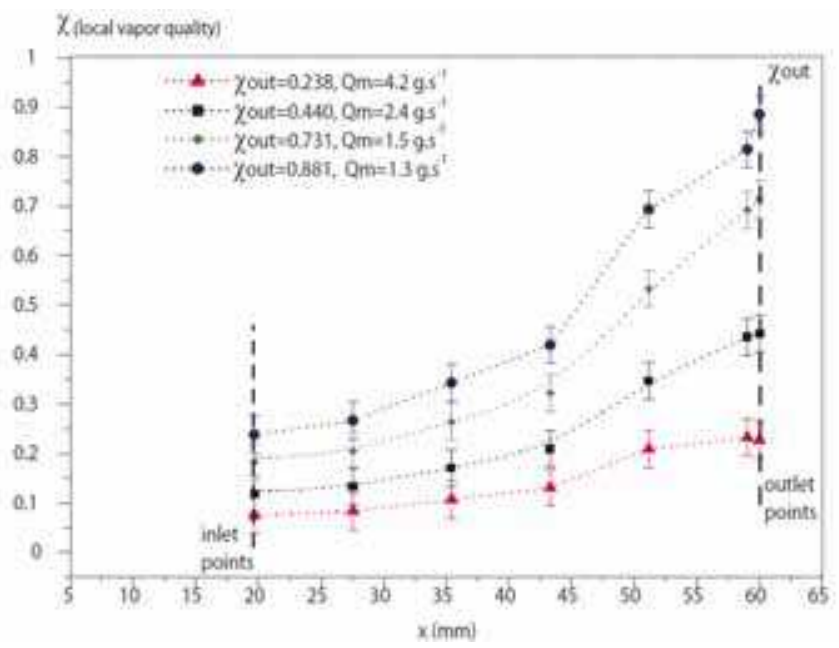

Fig. 20. Influence of local vapor quality as a function of the main flow axis $\left(\mathrm{Q}_{\mathrm{w}}=45 \mathrm{~kW} \cdot \mathrm{m}^{-2}\right)$. 
A second result shows a non linear evolution because in our case the heat flux density is not constant. Indeed, the $\mathrm{Q}_{w}$ calculated on the wall minichannel varies around $2 \%$. This result is explicit at the inlet minichannel where we observe a short decrease since the error estimation is higher around these points. Besides, at the outlet minichannel, the local vapour quality $(x=60 \mathrm{~mm})$ tends to reach a value corresponding to the global outlet vapour quality.

$$
\chi_{\mathrm{v}}^{\text {out }}=\left(\frac{\mathrm{Q}_{\mathrm{W}}^{\mathrm{v}}}{\mathrm{Q}_{\mathrm{w}}^{\text {Total }}}\right)
$$

When we are at the edges of our channel, the local value is close to the outlet vapour quality:

$$
\lim _{\mathrm{x} \rightarrow \mathrm{L}} \chi_{\mathrm{v}}(\mathrm{x})=\chi_{\mathrm{V}}^{\text {out }}
$$

Where $x$ is the abscissa of the minichannel and $L$ is the final length. This comparison is used to validate our results. Here, we have plot four tends of the local vapour quality as a function of the minichannel axis. We observe on Fig. 13, that the heat transfer coefficient profile for the terrestrial gravity decreases when the vapour quality increases. This is in good agreement with our experimental data under terrestrial gravity conditions. Indeed, as quality increases, the Kandlikar correlation predicts a steadily decreasing heat transfer coefficient. The nucleate boiling contribution diminishes while the forced-convective effect decreases and there is a steady drop in heat transfer coefficient with quality. However, the experimental results can only be compared during terrestrial gravity because when we are in microgravity and hypergravity, the correlations is no longer valid. Actually, we can't find a model that predicts the behaviour of the boiling heat transfer coefficient when the gravity level changes. Plus, with the increasing Re, the outlet vapour fraction is decreasing meaning that the average vapour fraction is lower and dry out has less influence on heat transfer.

\section{Conclusion and perspectives}

A study of two-phase flow regimes in a vertical rectangular minichannel is performed. Actually, flow boiling heat transfer in microgravity has received relatively little attention. Thus, the few experiments and the short duration of microgravity conditions do not allow a full understanding of the mechanisms controlling flow boiling heat transfers. But it is a starting point. In this study, we gathered all the results highlighted the influence of gravity on convective boiling in minichannels. Local values of wall surface temperature; heat flux and heat transfers were done and helped us to construct boiling curves. We perform analysis of the selected parameters which influence the mechanisms. Indeed, the analysis of temperature as a function of $g$ confirms that gravity has an influence on flow and heat transfer. The microgravity generates vapour pocket structures which fill the width of the minichannel and the heat transfer coefficient is locally higher. Consequently, we can assume that microgravity influences the appearance of the vapour bubbles whose size varies depending parameter $\mathrm{g}$. In the case of hypergravity and normal gravity, a classical bubbly flow structure is observed. Concerning the inverse method, we were able to solve a 3D IHCP. For the inverse methods, the sensors induce too many disturbances and accentuate the ill-posed character. These uncertainties lead to clear variations in the solution and particularly in the surface heat flux. One solution would be to add IR (infra-red) 
measurements while painting the lower face of the cement in black and placing a camera directly below and another would be to destroy the minichannels to estimate the locations of the thermocouples. In addition, all the experimental data are not totally transient. Indeed, we have some gravity phase changes which are steady so that using a normal steady approach to study convective boiling was successfully done. Thus, to use all our experimental data and to confirm our results, prediction of the convective boiling heat transfer coefficient requires a transient approach. That's why we need to take into account these dynamic instabilities for further results. In outgoing experiments, to deal with more experimental data from the Parabolic Flight campaign, we will perform this transient formulation.

\section{Acknowledgment}

We would especially like to thank the CNES (793/2002/CNES/8665) and ESA (MAP Boiling) for their financial support. We thank them for giving us access to the experimentation in microgravity on board the A300 Zero-G. We would also like to express our gratitude to Novespace ${ }^{\circledR}$ and more especially to Mr. Mora and Mr. Gai for their technical assistance during the campaigns PF52/CNES and PF53/ESA

\section{References}

Carey V. P. (1992). Liquid-Vapour Phase Change Phenomena, Hemisphere Publishing Corporation, New York

Kandlikar S. G.(2001). Fundamental issues related to flow boiling in minichannels and microchannels, Experiental Heat Transfer, Fluid Mechanics and Thermodynamics, Vol.1, Edizioni ETS, PISA, 2001.

Tadrist L. (October 2007). Flow Boiling in Microgravity Condition: Investigation Using Inverse Techniques. II of Micrograwity Science and Technology, October 26-28.

Yan Y. and Kenning D. B. R.(1998) Pressure fluctuations during boiling in a narrow channel. HTFS Research Symposium.

Kennedy J. E., Roach G. M., Dowling M. F., Abdel-Khalik S. I., Ghiaasiaan S. M., Jeter S. M., and Quershi Z. H.(February 2000). The onset of flow instability in uniformly heated horizontal microchannels. eburnal of Heat Transfer, 122:118-125.

Qu W., Mudawar I. (2003). Flow boiling heat transfer in two-phase micro-channel heat sinks: Experimental investigation and assessment of correlations methods. International eburnal of Heat and Mass Transfer, 46.

Brutin D. and Tadrist L. (October 2006). Destabilization mechanisms and scaling laws of convective boiling in a minichannel. AIAA eburnal of Thermophysics and Heat Transfers, 20.

Hestroni G. et al.(2005). Fluid flow in microchannels. International eburnal of Heat and Mass Transfer, pages 1982-1998.

Tran T.N., Wambsganss M.W. and D.M. (1996). Small circular and rectangular channel boiling with two refrigerants, International eburnal of Multiphase Flow, pages 485-498.

Thome J.R. (2004). Boiling in microchannels: a review of experiment and theory. International cburnal of Heat and Fluid Flow, pages 128-139.

Kew P.A. and Cornwell K. (1997). Correlations for the prediction of boiling heat transfer in small-diameter channels. Applied Thermal Engineering, pages 705-715. 
Ledinegg M. (1938). Instability flow during natural forced circulation, Warme, 61(8) :891-898.

P. A. Kew and K. Cornwell. Confined bubble flow and boiling in narrow spaces. In 2nd, Int. Heat Transfer Conference, Brighton 7, pages 473-478, 1994.

J.V. Beck, B. Blackwell, C.R. St. Clair (1985). Inverse Heat Conduction, Ill-Posed Problems, Wiley Interscience, New York.

Brebbia C.A., Telles J.C.F. and Wrobel L.C.(1984). Boundary Element Techniques, SpringerVerlag, Berlin and New York.

Le Niliot C., Lefèvre F. (2001). A method for multiple steady line heat sources identification in a diffusive system: application to an experimental 2D problem, International eburnal of Heat and Mass Transfer, vol. 44, pp. 1425-1438.

Press W.H., Flannery B. P., Teulossky S. A., Vetterling W. T. (1990). Numerical Recipes, Cambridge.

Hansen P.C. (1998). Rank-Deficient and discrete Ill-posed Problems, SIAM, Philadelphie. 


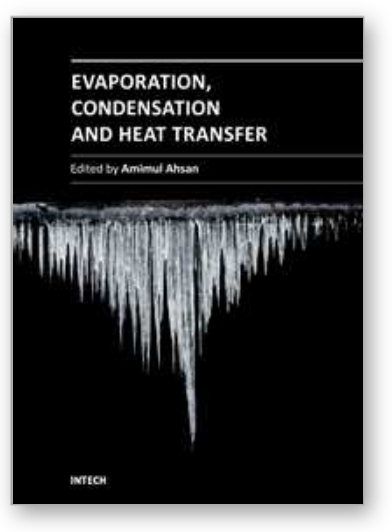

\author{
Evaporation, Condensation and Heat transfer \\ Edited by Dr. Amimul Ahsan
}

ISBN 978-953-307-583-9

Hard cover, 582 pages

Publisher InTech

Published online 12, September, 2011

Published in print edition September, 2011

The theoretical analysis and modeling of heat and mass transfer rates produced in evaporation and condensation processes are significant issues in a design of wide range of industrial processes and devices. This book includes 25 advanced and revised contributions, and it covers mainly (1) evaporation and boiling, (2) condensation and cooling, (3) heat transfer and exchanger, and (4) fluid and flow. The readers of this book will appreciate the current issues of modeling on evaporation, water vapor condensation, heat transfer and exchanger, and on fluid flow in different aspects. The approaches would be applicable in various industrial purposes as well. The advanced idea and information described here will be fruitful for the readers to find a sustainable solution in an industrialized society.

\title{
How to reference
}

In order to correctly reference this scholarly work, feel free to copy and paste the following:

Sébastien Luciani (2011). Two Phase Flow Experimental Study Inside a Microchannel: Influence of Gravity Level on Local Boiling Heat Transfer, Evaporation, Condensation and Heat transfer, Dr. Amimul Ahsan (Ed.), ISBN: 978-953-307-583-9, InTech, Available from: http://www.intechopen.com/books/evaporationcondensation-and-heat-transfer/two-phase-flow-experimental-study-inside-a-microchannel-influence-ofgravity-level-on-local-boiling-

\section{INTECH}

open science | open minds

\author{
InTech Europe \\ University Campus STeP Ri \\ Slavka Krautzeka 83/A \\ 51000 Rijeka, Croatia \\ Phone: +385 (51) 770447 \\ Fax: +385 (51) 686166 \\ www.intechopen.com
}

\author{
InTech China \\ Unit 405, Office Block, Hotel Equatorial Shanghai \\ No.65, Yan An Road (West), Shanghai, 200040, China \\ 中国上海市延安西路65号上海国际贵都大饭店办公楼 405 单元 \\ Phone: +86-21-62489820 \\ Fax: +86-21-62489821
}


(C) 2011 The Author(s). Licensee IntechOpen. This chapter is distributed under the terms of the Creative Commons Attribution-NonCommercialShareAlike-3.0 License, which permits use, distribution and reproduction for non-commercial purposes, provided the original is properly cited and derivative works building on this content are distributed under the same license. 